\title{
Stimulus-induced Rhythmic, Periodic, or Ictal Discharges (SIRPDs) associated with seizures in cefepime neurotoxicity
}

Descargas ictais, periódicas ou rítmicas induzidas por estímulos (SIRPIDs) associadas a crises epilépticas na neurotoxicidade por cefepime

Valmir Passarelli, Maria Paula Oliveira Moutinho da Conceição, Eduardo Sturzeneker Trés, José

Furtado Alves-Junior, Meire Argentoni Baldocchi

Cefepime was started for a patient with urinary tract infection and renal failure. The next day, she started confusion and seizures. EEG recorded Stimulus-induced Rhythmic, Periodic, or Ictal Discharges (SIRPIDS) associated with seizures (Figure). Cefepime was discontinued. Subsequent EEG demonstrated only slowed background (SB).

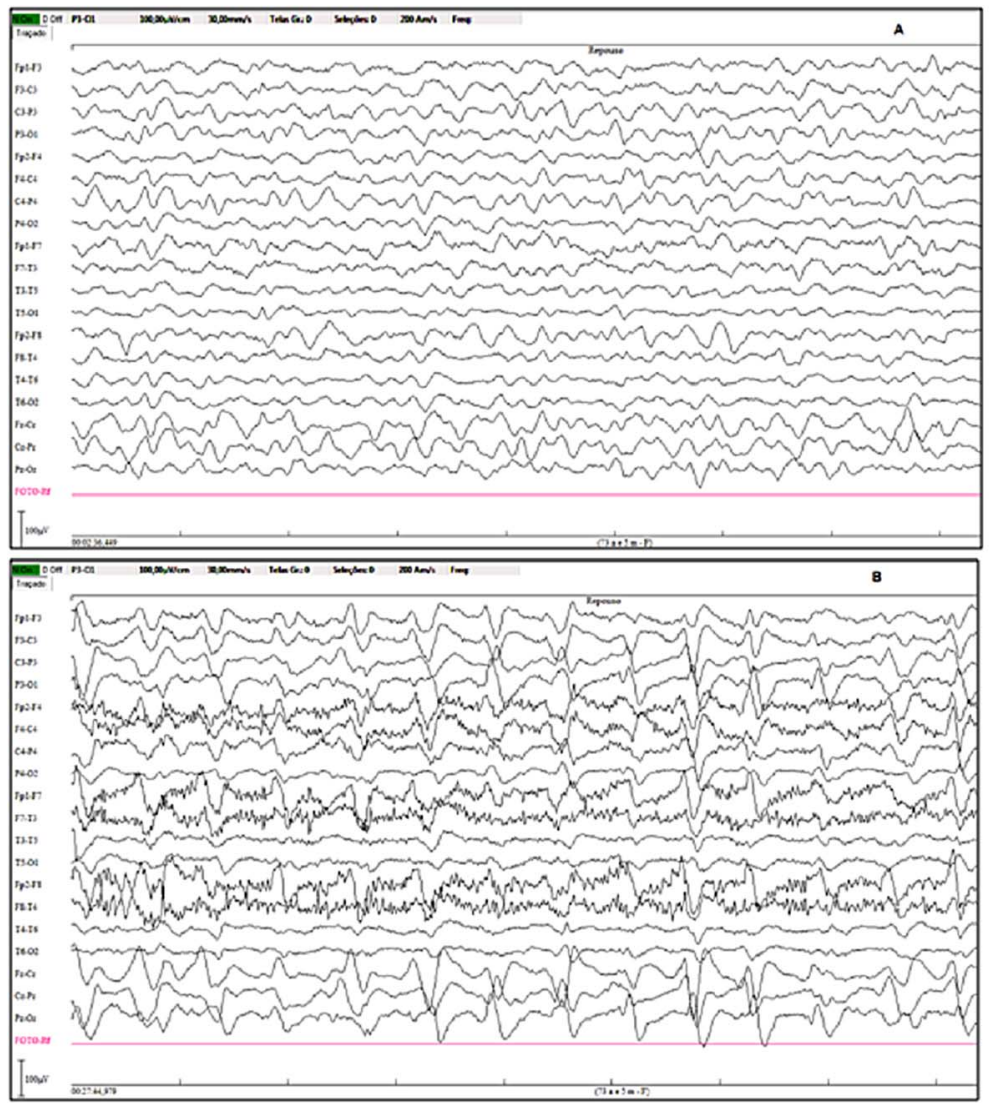

Figure. Initial EEG. Prior to stimulation, slowing of background (A). After sternal rub, bilateral triphasic waves (repeated every 0.5 s) prominent in the fronto-central regions of the two hemispheres, left and median predominated (B). This activity was associated with jerks affecting right upper limb. 
The EEG in cefepime neurotoxicity $(\mathrm{CN})$ is considered non-reactive to stimulation, and characterized for SB associated or not with periodic discharges, including triphasic waves (TWs). Discordantly, we describe SIRPIDS in $\mathrm{CN}^{1,2}$.
Our report and the recent description of repeated TWs as ictal pattern ${ }^{3,4}$ demonstrate that at least some discharges in $\mathrm{CN}$ are epileptic related.

Alerting stimuli activate the arousal circuitry, and, when combined with hyperexcitable cortex, result in SIRPIDS and seizures ${ }^{5}$.

\section{References}

1. Jallon P, Fankhauser L, Du Pasquier R, et al. Severe but reversible encephalopathy associated with cefepime. Neurophysiol Clin 2010;30:383-386.

2. Bragatti JA, Rossato R, Ziomkowski S, Kliemann FAD. Cefepime-induced encephalopathy: clinical and electroencephalographic features in seven patients. Arq Neuropsiquiatr 2005;63:87-92
3. Bragatti JA. The role of triphasic waves in the care of critically ill patients. Clin Neurophysiol 2013;124:1924.

4. Sutter R, Stevens RD, Kaplan PW. Significance of triphasic waves in patients with acute encephalopathy: A nine-year cohort study. Clin Neurophysiol 2013;124:1952-1958.

5. Hirsch LJ, Pang T, Claassen J, et al. Focal motor seizures induced by alerting stimuli in critically ill patients. Epilepsia 2008;49:968-973. 